\title{
Analysis on the Willingness of Rural Women's Moving to Towns in Henan Province
}

\author{
Qin Liu',a, Zhenlei Shi',b, \\ ${ }^{1}$ Beijing Jiaotong University, China \\ ${ }^{2}$ Beijing Jiaotong University, China \\ a15120557@bjtu.edu.cn, bzhlshi@bjtu.edu.cn
}

Keywords: rural women, move to town, Henan, will analysis.

\begin{abstract}
Based on the practice of new urbanization in Henan Province, this paper, based on the field investigation of Luyi County in Henan Province in March 2017, takes the rural female labor force in Luyi County of Henan Province as the research object and collects the data in the form of questionnaires. The rural women's labor force relocation in Henan Province is descriptive, and the Logit model is used for empirical analysis. The results of empirical analysis show that individual factors such as age, educational level, professional labor skills, marital status and monthly income are the main factors that determine the willingness of rural women to relocate to urban areas. It is therefore recommended that the Government should focus on the employment situation, education and training of rural women, improving the competitiveness of rural women's employment and the ability to adapt to urban life.
\end{abstract}

\section{Introduction}

With the continuous development of economy and society, more and more rural labor force move to the town. In the process of urbanization, the rural labor force's behavior affects the speed and quality of the urbanization process. The process of urbanization of farmers at least experience the career and residence of two aspects of the change. However, our country's current rural labor force is only to achieve a career change, the residence is still stranded in the countryside or at the edge of the city [1]. In the transformation of the peasant from the employment structure to the settled state, women as an important part of the labor force and an important participant in family decision-making, its great role cannot be ignored. In fact, in the context of the new urbanization, whether rural women can obtain stable work and life in the cities and finally realize the change of identity and status, has become the focus of contemporary government and scholars. Therefore, it is indispensable to study the willingness of rural women to move to the town. At present, there are many researches on labor mobility at home and abroad, but there are few studies on the empirical study on the willingness of rural women to move to urban areas. This paper will study the rural women's labor force as the research object, mainly to study the rural women in Henan Province to move out of the town's willingness to analyze the main factors affecting their relocation of the town.

\section{Migrant Rural Women's Employment Status and Relocation Wishes in Henan Province}

The main purpose of this survey is to investigate the overall situation of rural women labor migrant workers in Luyi County, Henan Province. The main contents of the survey include the personal characteristics of the labor force, family characteristics, employment and living conditions, willingness to move, etc., and the investigation site to Luyi County. In view of the need of research, this paper chooses some of the relevant variables to analyze the willingness of migrant rural migrant workers to relocate to urban areas. There are 177 valid sample data in this paper, of which 126 are willing to move to the town, accounting for $71.2 \%$ of the sample, and 51 are reluctant to move to the town, accounting for $28.8 \%$ of the sample. 
2.1 The Basic Situation of Migrant Rural Women. In the respondents, $6.48 \%$ are at the age of 18 years, $69.06 \%$ are in $18-28$ years old, $12.23 \%$ are in $29-39$ years old, $10.79 \%$ are in the range of 40-55 years, and over the age of 55 accounted for $1.44 \%$. Overall, 20-year-old young rural women are the main body of migrant workers. Urban employment in rural women is the young trend.

In terms of the educational level of the respondents, primary school and the following accounted for $21.58 \%$, junior high school accounted for $24.46 \%$, high school or secondary school accounted for $7.92 \%$, college and above accounted for $46.04 \%$. The overall data show that a large part of migrant rural women have a college education. The results show that rural women in this survey have the basic ability to express their wishes.

From the marriage situation, migrant rural women accounted for $51.80 \%$ of unmarried women, and married women is the proportion of $48.20 \%$.

2.2 Employment and Income of Women in Rural Areas. Among the respondents accounted for $18.64 \%$ in the manufacturing sector. Residents and other services, accommodation and catering industry as well as wholesale and retail trade also accounted for a certain proportion, accounting for $15.25 \%, 14.69 \%, 14.12 \%$.

From the employment area, the rural women labor to migrant workers in the region to large cities up to $53.11 \%$. Followed by small and medium-sized cities accounted for $34.46 \%$. Local counties and township enterprises were only $5.65 \%$ and $6.78 \%$.

Among the respondents, the monthly income of rural women in urban areas was mostly between 2000 and $4000.29 .38 \%$ of rural women in the monthly income was $2000-3000$ yuan. $33.33 \%$ of rural women in the monthly income was 3000-4000 yuan.

2.3 Analysis of the Reasons for the Relocation of Urban. 28.09\% of the rural women moved to the town in order to make their children better educated, $19.33 \%$ of the rural women moved to the town for their own greater development. There are still some women because the city has more employment space, urban civilization, high quality of life, and in order to allow parents to enjoy.

\section{Quantitative Analysis of the Factors Affecting the Rural Women Labor Flow}

In order to further comprehensively analyze the comprehensive effect of various factors on the willingness of rural women to relocate to urban areas, the author uses Logit multiple linear regression model to carry on further measurement model analysis.

3.1 Research Methods. In social and economic activities, people often encounter multiple choice problems, when the search for the data is discrete and non-continuous, the conventional regression model is not suitable for such a choice of decision-making situation. In most cases, we often encounter situations where the dependent variable is a binary value, such as the occurrence or absence of an event, presence or absence, and so on. The binary selection of the Logit model can effectively examine correlation between the dependent variable of such binary response and a set of influencing factors (independent variables) [2]. The specific expression of the model is as follows:

$$
P\left(Y_{i}=0\right)=\frac{1}{1+\exp \left(\beta_{0}+\beta_{1} x_{i 1}+\beta_{2} x_{i 2}+\ldots+\beta_{i} x_{i j}\right)} P\left(Y_{i}=1\right)=\frac{\exp \left(\beta_{0}+\beta_{1} x_{i 1}+\beta_{2} x_{i 2}+\ldots+\beta_{i} x_{i j}\right)}{1+\exp \left(\beta_{0}+\beta_{1} x_{i 1}+\beta_{2} x_{i 2}+\ldots+\beta_{i} x_{i j}\right)}
$$

Where $\mathrm{x} 1, \mathrm{x} 2, \ldots, \mathrm{xi}$ are the independent variables associated with $\mathrm{Y}$, assuming that the n-group sample data obtained is (xi1, xi2, .., xj, Yi), Yi is a random value of 0 or 1 variable. $\beta 0$ is a constant term independent of the factors $x i j$, and $\beta 1, \beta 2, \ldots, \beta i$ are the regression coefficients. In this paper, the binary selection Logit model is used to test the relocation of rural women's labor force (relocation or non-relocation) and each variable [3].

3.2 Variable Design. This paper chooses the relocation intention as the explanatory variable. In the questionnaire, when asked about "the future intention of settling home", If the respondent replies to the "town", it is willing to move to the town to go to the value of 1 . This paper chooses age, education level, whether it has the labor skills, marital status, the monthly income of migrant workers, working places as explanatory variables. The specific situation is shown in Table 1: 
Table 1. Variable Explanation

\begin{tabular}{|c|c|}
\hline $\begin{array}{l}\text { Variable } \\
\text { name }\end{array}$ & Variable declaration \\
\hline $\mathrm{X} 1$ & $\begin{array}{c}\text { The age of the respondents }(1=18 \text { years of age; } 2=18-28 \\
\text { years old; } 3=29-39 \text { years old; } 4=40-55 \text { years old; } 5=55 \\
\text { years old })\end{array}$ \\
\hline $\mathrm{X} 2$ & $\begin{array}{c}\text { Education level of respondents }(1=\text { primary school and } \\
\text { below; } 2=\text { junior high school; } 3=\text { high school or technical } \\
\text { secondary school; } 4=\text { college degree or above })\end{array}$ \\
\hline $\mathrm{X} 3$ & $\begin{array}{l}\text { Respondents with or without professional labor skills } \\
\qquad(1=y e s ; 0=\text { no })\end{array}$ \\
\hline $\mathrm{X} 4$ & Marital status of respondents ( $1=$ married; $0=$ unmarried $)$ \\
\hline $\mathrm{X} 5$ & $\begin{array}{l}\text { Respondents to work out the monthly income }(1=\text { less } \\
\text { than } 2000 \text { yuan; } 2=2000-3000 \text { yuan; } 3=3000-4000 \text { yuan; } \\
4=4000-5000 \text { yuan; } 5=5000 \text { yuan or more })\end{array}$ \\
\hline X6 & $\begin{array}{l}\text { Respondents to work place }(1=\text { township; } 2=\text { local } \\
\text { county; } 3=\text { medium and small cities; } 4=\text { big cities })\end{array}$ \\
\hline $\mathrm{Y}$ & $\begin{array}{l}\text { Analysis of willingness to move to town ( } 1=\text { willing; } 0= \\
\text { unwilling) }\end{array}$ \\
\hline
\end{tabular}

3.3 Binary Logistics Regression Analysis. The purpose of this analysis is to determine the main influencing factors of rural women's labor migration intention, because the probability variable Y $(0$, 1) of rural women's labor force is a bivariate variable, so the author uses the binary logistics regression model, Low explanatory variables removed, and then determine the main influencing factors of rural women's labor migration intention.

Table 2. Regression Analysis Results of Rural Women's Relocation to Urban Wishes

\begin{tabular}{ccccccc}
\hline & B & S.E. & Wald & $\begin{array}{c}\text { Degrees } \\
\text { of } \\
\text { freedom }\end{array}$ & Saliency & Exp(B) \\
\hline Age & -0.553 & 0.273 & 4.089 & 1 & 0.043 & 0.575 \\
\hline $\begin{array}{c}\text { Degree of } \\
\text { Education }\end{array}$ & 0.939 & 0.204 & 21.223 & 1 & 0 & 2.557 \\
\hline Labor skill & 1.099 & 0.44 & 6.238 & 1 & 0.013 & 3 \\
\hline Marital status & -0.574 & 0.564 & 1.038 & 1 & 0.308 & 0.563 \\
\hline $\begin{array}{c}\text { Monthly } \\
\text { income of } \\
\text { working }\end{array}$ & 0.63 & 0.226 & 7.736 & 1 & 0.005 & 1.877 \\
\hline Working place & -0.019 & 0.241 & 0.006 & 1 & 0.939 & 0.982 \\
\hline constant & -2.63 & 1.126 & 5.459 & 1 & 0.019 & 0.072 \\
\hline
\end{tabular}

Rural women with a higher educational level are more likely to move to towns. From the estimate of the coefficient, the degree of education has a large positive impact on the willingness to move to rural women. Which indicates that the higher the educational level, will have the higher the expected return on the future. High-income opportunities are more, and the relocation of the psychological costs are smaller. The other hand, the higher the degree of education, the more likely to change the behavior and lifestyle to adapt to urban life norms. The process of re-socialization than the degree of culture Low people are easier.

The more young unmarried women, the more inclined to move to town. The negative coefficient of age is negative, indicating that the rural women are older, the less likely they will be relocated in the next period of time. With the increasing age of rural women, the ability and enthusiasm to relocate 
in the future will gradually weaken. To a certain extent, it affect the future relocation of urban will [4].

Age and marriage status of the two estimates of the coefficient is negative. It can be interpreted as unmarried young women because there is no family and children's constraints, whether the relocation can be out of personal wishes. And with the employment structure brought about the lifestyle changes. Their behavior is more likely to meet the norms of urban life. The married is to take into account the overall interests of the family. The town life means to bear greater spending and re-establish the network of interpersonal relationships. The high cost of relocation and out of family life considerations make them hesitant.

Rural women with professional labor skills are more likely to move to town. Rural women with professional labor skills have a significant positive correlation with their relocated towns, and an increase of $109.9 \%$ in employment opportunities for every additional range of labor skills. The rural women who participated in the training of professional skills have a much higher probability of moving than those who have not participated in professional skills training.

The monthly income of rural women has a positive effect on the relocation intention of women in rural areas. From the estimation of the coefficient, the monthly income of rural women has a significant positive effect on the relocation intention of women in rural areas. It shows that the higher the wage income of rural women more inclined to stay in the town. It indicates that the economic factors are still the most important influencing factors of rural women's labor relocation. For rural women as a rational economic man, the ability to earn higher incomes will greatly enhance the likelihood of moving to their towns.

Rural women's working places have a certain impact on the willingness of rural women to move. There is a negative correlation between the working place of rural women and the willingness of rural women to move forward, but it is not obvious. It is more difficult to stay for rural women who work in big cities, mainly taking into account the cost of living. In the big city, the greater the cost of living, the greater the pressure of life, and the more difficult to stay. But the smaller towns have the opportunity to settle down.

\section{The Main Conclusions and Revelation}

This paper takes the rural women in Henan Province as the research subject, and examines the willingness and influencing factors of migrant rural women. The results show that $71.2 \%$ of rural women are willing to move to towns and $28.8 \%$ of rural women are reluctant to move to towns. Indicating that a considerable proportion of rural women have a clear willingness to move, and the higher the level of education, high non-agricultural wages, professional labor skills, and unmarried young women, the more inclined to move to town.

This paper also makes a statistical analysis of the reasons why rural women are willing to move and do not want to move to town. The results show that rural women are willing to move to the town that the most important reason is to have better education for their children, followed by urban employment opportunities, hoping that they have better development space, and high quality of life. In the process of farmers' transformation to the public, rural women play an important role as an important component of the labor force and an important participant in family decision-making [5].

Therefore, in order to promote the new urbanization and better play the role of rural women, rural women need to improve the level of education, to strengthen rural women's education and training. The higher education level has a positive effect on the willingness of rural women to move. A large number of surveys and empirical studies have confirmed that rural women's low cultural quality and lacking of skills are important reasons leading to low levels of employment and income levels [6]. And this study also found that a higher level of education has a positive influences. It can be seen, whether from the perspective of improving the overall quality of the rural population, or to promote the transfer of female labor to a higher level of industry perspective, improving the rural women's human capital stock is an urgent need to solve the problem. At the same time, strengthening vocational skills training is also an important way to promote rural women to move to town. 
Professional skills training can, to some extent, compensate for the lack of formal education. To this end, in the consolidation and strengthening of rural basic education, according to market demand, multi-level and multi-faceted rural women's vocational and technical training, give psychological quality, values and other aspects of guidance and improve the ability to adapt to urban life and deal with problems.

\section{References}

[1] Liu Hua and Su Chun, "Empirical Analysis on Willingness of Staying in City of Rural Female Labor in Jiangsu Province", China Rural Economy, no.9 pp.42-47, 2005.

[2] Jichuan Wang and Zhigang Guo, "Logistic regression model-method and application", Beijing: higher education press, vol.89, no.58 pp.97-102, 2011.

[3] Xiaojian $\mathrm{Li}$ and $\mathrm{Li}$ Jun, "Rural residents moved to intend to influence factors analysis", Economic geography, vol.3, no.28 pp. 454-459, May 2008.

[4] Guangshuai Cheng and Wan Neng, "Causes and Effects of the Rural Female Marriage Migrants", Northwest Population Journal, vol.9, no.4, pp.31-33, April 2003.

[5] He Xiong and Chen Pan, "An empirical analysis of the rural women moved to cities and towns will state - in Ezhou, Huangshi, Xiantao, for example", China's population, resources and environment, vol.23, no.1 pp.97-102, 2013.

[6] Su Qun and Chunfang Zhou, "Rural Women in Town Employment and Moved to Intend to Analysis", Agricultural Economy Problems, no.7 pp.30-34, 2005. 